\title{
Studies on the C-Terminal Amino Acid of Eel Hemoglobin*
}

\author{
Hideomi Amano, Kanehisa Hashimoto, and Fumio MatsuUra** \\ (Received October 27, 1971)
}

\begin{abstract}
The four hemoglobin components $\left(F_{1}, F_{2}, S_{1}\right.$, and $\left.S_{2}\right)$ of eel, Anguilla japonica, were analyzed for C-terminal amino acids by the hydrazinolysis method. Results obtained are summarized as follows: (1) In the cases of components $F_{1}$ and $F_{2}$, the valyl and the acetylated polypeptide chain have a His and an Arg residue, respectively, as C-terminus, while in the cases of components $S_{1}$ and $S_{2}$ both chains have exclusively an Arg residue per chain as Cterminus. (2) Together with the fact that components $S_{1}$ and $S_{2}$ are lacking in BoHR effect, whereas components $F_{1}$ and $F_{2}$ show large BoHR effect, the present results seem to give a new and strong support to the suggestion based on some indirect evidence with mammalian hemoglobins that the $\mathrm{C}$-terminal His residues of $\beta$ chains of hemoglobin are remarkably responsible for its BoHR effect and oxygen affinity.
\end{abstract}

As reported previously, ${ }^{1)}$ the four hemoglobin $(\mathrm{Hb})$ components of eel all are composed of two valyl and two acetylated polypeptide chains. In the preceding papers, ${ }^{2,3)}$ the authors indicated on the basis of the $\mathrm{N}$-terminal sequences of those chains that their acetylated and valyl chains are rather comparable to the $\alpha$ and the $\beta$ chains of the other vertebrate $\mathrm{Hb}$ 's respectively.

In the case of higher vertebrate, the $\alpha$ and the $\beta$ chain of $\mathrm{Hb}$ almost exclusively possess an Arg and a His residue, respectively, as C-terminus. The C-terminus of the lower vertebrate $\mathrm{Hb}$ has not extensively been studied so far. Incidentally it has recently been suggested by several authors ${ }^{4-\varepsilon}$ ) that the $\mathrm{C}$-terminal His residues of $\beta$ chains of human and the other mammalian Hb's are remarkably responsible for their BoHR effect and oxygen affinity. It is not clear, however, whether the same is also true for the $\mathrm{Hb}$ of lower vertebrate including fish. In this connection, the relatively frequent occurrence of BoHR effect-absent $\mathrm{Hb}$ is one of the specific characters of fish $\mathrm{Hb}$. In the case of eel, for example, $\mathrm{Hb}$ component $\mathrm{F}$ shows a large BoHR effect, while $\mathrm{S}$ dose not. ${ }^{7)}$ Hence, it seemed interesting also from this viewpoint to examine the $\mathrm{C}$-terminus of fish $\mathrm{Hb}$.

The above situation aroused the authors to analyze those $\mathrm{Hb}$ components of eel for C-termini, and present investigation was undertaken.

\section{Experimental}

Materials: Four $\mathrm{Hb}$ components $\left(\mathrm{F}_{1}, \mathrm{~F}_{2}, \mathrm{~S}_{1}\right.$, and $\left.\mathrm{S}_{2}\right)$ of eel, Anguilla japonica, were

* An outline of this article was presented to the Ann. Meetg. of Japan. Soc. Sci. Fish., Tokyo, April $3,1971$.

** Lab. of Marine Biochem., Fac. of Agr., The Univ. of Tokyo, Bunkyo-ku, Tokyo (天野秀臣 ·橋 本周久. 松浦文雄：東京大学農学部) 
prepared by the method described previously." Each $\mathrm{Hb}$ component was treated with a $\mathrm{HCl}$-acetone mixture to split into globin and heme moiety. The globin precipitates formed were collected by centrifugation, dried in vacuo, and used for preparation of its constituent polypeptide chains by the following method.

Preparation of valyl and acetylated polypeptide chains: On the basis of the results of some preliminary experiments, both polypeptide chains of each globin were prepared by the use of zone electrophoresis in the presence of a concentrated urea as follows.

About $100 \mathrm{mg}$ of each globin thus prepared was dissolved in $7 \mathrm{ml}$ of $7 \mathrm{M}$ urea-0.1 M veronal buffer containing $1 \% \beta$-mercaptoethanol, $\mathrm{pH} 8.0$, and allowed to stand at room temperature for $5 \mathrm{hr}$. After eliminating trace amounts of insoluble materials by centrifugation (3,000 rpm, $15 \mathrm{~min}$ ), the supernatant was subjected to starch block electrophoresis using a column of $5 \times 2 \times 45 \mathrm{~cm}$ in size and the same buffer system as above except the concentration of $\beta$-mercaptoethanol was changed to $0.2 \%$. The electrophoresis was carried out for $16 \mathrm{hr}$ in a cold room under a constant current of $15 \mathrm{~mA}$ in the cases of components $F_{1}$ and $F_{2}$ and $24 \mathrm{~mA}$ in the cases of $S_{1}$ and $S_{2}$. After the run, a strip of filter paper was pressed onto the starch block. After drying, the paper was stained with amido black $10 \mathrm{~B}$. Referring to the protein pattern thus provided, both polypeptide bands of each globin were located and extracted with the above-mentioned buffer. To those extracts previously dialyzed, was added about 10 -fold volumes of acetone. The precipitates produced were collected by centrifugation, washed with acetone, and dried for more than three days over $\mathrm{P}_{2} \mathrm{O}_{5}$ in a vacuum desiccator. Those polypeptide chain preparations were dissolved in $1.4 \mathrm{M}$ formate buffer, $\mathrm{pH} 1.9$, and checked for homogeneity by starch gel electrophoresis at $\mathrm{pH} 1.9$ according to MULLER $^{8 /}$ and then, used for C-terminal analysis as follows.

Assay of C-terminal amino acid: Both polypeptide chains from each $\mathrm{Hb}$ component were analyzed for $\mathrm{C}$-terminus by the hydrazinolysis method approximately after TAKAHASHI. Dried preparation (usually $30 \mathrm{mg}$ ) of each polypeptide chain was hydrazinolyzed with $1 \mathrm{ml}$ of anhydrous hydrazine at $100^{\circ} \mathrm{C}$ for $10 \mathrm{hr}$ in a sealed tube. Then, the lyzates were dried over concentrated $\mathrm{H}_{2} \mathrm{SO}_{4}$ in vacuo, dissolved in ca. $2 \mathrm{ml}$ of distilled water, and treated twice with enanthaldehyde for $30 \mathrm{~min}$ each in order to eliminate various amino acid hydrazides formed. The amino acids in those aqueous solutions were assayed by the DNP method. In calculation of the number of C-terminal residue in each polypeptide chain, an assumed molecular weight of 17,000 was employed throughout all the chains. As the recovery ratios of $\mathrm{C}$-terminal amino acids after hydrazinolysis, the values reported by NiU et $a l .^{101}$ were adopted here.

\section{Results}

Preparation of polypeptide chains: As for the preparation method of both chains, 
several methods were preliminarily applied to those eel globins and their results compared until the zone electrophoresis as described above was found most satisfactory. Under the conditions selected, each of the globins was separated into two bands, as schematically shown in Fig. 1. It was demonstrated by examining the reactivity with the DNP reagent that the fast-moving band corresponded to the acetylated polypeptide chain and the slowmoving band to the valyl chain with any of the four $\mathrm{Hb}$ components.

All of the polypeptide chain preparations thus prepared presented single bands in starch gel

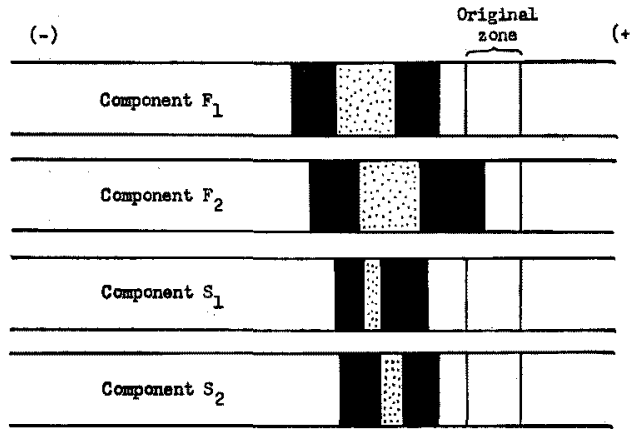

Fig. 1. Separation by starch block electrophoresis of the four $\mathrm{Hb}$ components of eel into their constituent polypeptide chains.

A $7 \mathrm{M}$ urea $-0.1 \mathrm{M}$ veronal buffer containing $0.2 \% \beta$-mercaptoethanol, $\mathrm{pH} 8.0$, was used. Duration of electrophoresis, $16 \mathrm{hr}$. See the text for further details. electrophoresis at $\mathrm{pH}$ 1.9. Yield of each polypeptide chain preparation was about 15 mg irrespective of the type of $\mathrm{Hb}$ when approximately $100 \mathrm{mg}$ of $\mathrm{Hb}$ was used as the starting material.

C-Termini of polypeptide chains: To begin with, the valyl polypeptide chains of the four $\mathrm{Hb}$ components were analyzed for $\mathrm{C}$-terminal amino acid. In the case of component $F_{1}$ or $F_{2}$, the ethyl acetate-soluble fraction presented a clear spot of DNP-His together with far fainter spots of DNP-Gly, -Ser, and -Asp on the LEvY's two-dimensional paper chromatogram. In the case of component $S_{1}$ or $S_{2}$, DNP-ornithine appeared as the main spot, besides minor to trace spots of DNP-Gly, -Ser, and -Asp.

Then, quantitative determinations of those DNP-amino acids were attemped to give the results in Table 1. DNP-ornithine detected with components $S_{1}$ and $S_{2}$ is presented here as Arg from which it was originated. In the cases of components $F_{1}$ and $F_{2}$, His was determined to be 0.92 and 0.82 mole, respectively, per mole of valyl chain, overwhelmingly surpassing the other amino acids all of which were estimated to be less than 0.03

Table 1. Amino acids detected in the hydrazinolyzates of valyl polypeptide chains from the four $\mathrm{Hb}$ components. Assayed by the DNP method.

\begin{tabular}{clllll}
\hline \multirow{2}{*}{ Hb component } & \multicolumn{5}{c}{ Amino acids, mole/mole of chain } \\
\cline { 2 - 6 } & Arg* & His & Gly & Ser & Asp \\
\hline$F_{1}$ & 0 & 0.92 & 0.01 & 0.02 & 0.02 \\
$F_{2}$ & 0 & 0.82 & 0.02 & 0.03 & 0.03 \\
$\mathrm{~S}_{1}$ & 0.90 & 0 & 0.03 & 0.04 & trace \\
$\mathrm{S}_{2}$ & 0.98 & 0 & 0.04 & 0.04 & trace \\
\hline
\end{tabular}

\footnotetext{
* Detected as DNP-ornithine.
} 
mole per mole. Hence, the valyl polypeptide chains of both $\mathrm{Hb}$ components are thought to possess 1 mole of $\mathrm{C}$-terminal His per mole.

In the cases of components $S_{1}$ and $S_{2}, 0.90$ and 0.98 mole, respectively, of DNPornithine were detected per mole of valyl polypeptide chain, setting aside far less amounts of DNP-derivatives of several other acids. Therefore, the C-termini of their valyl chains are supposed to be Arg at 1 mole per mole.

In analysis of C-termini of the acetylated polypeptide chains conducted similarly, on the other hand, the ethyl acetate-soluble fractions from the four $\mathrm{Hb}$ components all gave a large and strongly yellow spot of DNP-ornithine, and several minor spots corresponding to DNP-Gly, -Ser, and -Asp on the LEvy's paper chromatograms. Then, those DNP-amino acids were quantitatively determined. As shown in Table 2, 0.710.98 mole of DNP-ornithine per mole of polypeptide chain was detected as C-terminus throughout the four $\mathrm{Hb}$ components, besides negligible amounts of several amino acids. Therefore, those acetylated polypeptide chains are considered to possess 1 mole of $\mathrm{C}$ terminal Arg per mole, irrespective of the type of $\mathrm{Hb}$. Similarly, HILSE et al. ${ }^{11)}$ also found 1 mole of Arg per mole as the C-terminus of each of the acetylated chains in the two types of carp $\mathrm{Hb}$.

Table 2. Amino acids detected in the hydrazinolyzates of acetylated polypeptide chains from the four $\mathrm{Hb}$ components. Assayed by the DNP method.

\begin{tabular}{cccccc}
\hline \multirow{2}{*}{ Hb component } & \multicolumn{5}{c}{ Amino acids, mole/mole of chain } \\
\cline { 2 - 6 } & Arg* & His & Gly & Ser & Asp \\
\hline$F_{1}$ & 0.73 & 0 & 0.01 & 0.03 & 0.01 \\
$F_{2}$ & 0.96 & 0 & 0.02 & 0.03 & 0.02 \\
$S_{1}$ & 0.98 & 0 & 0.03 & 0.05 & trace \\
$\mathrm{S}_{2}$ & 0.71 & 0 & 0.05 & 0.05 & trace \\
\hline
\end{tabular}

* Detected as DNP-ornithine.

The DNP-derivatives of several amino acids other than the main amino acids occurring in the hydrazinolyzates seem to have been originated from the hydrazides of some amino acids by some side reactions, since those hydrazides are reported to be hydrolyzed to the corresponding amino acids during the enanthaldehyde treatment. ${ }^{\text {) }}$

With any polypeptide chain of the four Hb components, no DNP-amino acids were detected in the aqueous phase after the ethyl acetate extraction.

\section{Discussion}

Thus it can be concluded that in the cases of components $F_{1}$ and $F_{2}$ the valyl and the acetylated polypeptide chain have a His and an Arg residue, respectively, as C-terminus, while in the cases of $S_{1}$ and $S_{2}$ both chains have exclusively an Arg residue per chain as C-terminus. 
As the authors ${ }^{3 /}$ previously indicated on the basis of the N-terminal sequences of eel $\mathrm{Hb}$ components, their acetylated and valyl polypeptide chains are comparable to the $\alpha$ and the $\beta$ chains, respectively, of the other vertebrate Hb's. Throughout many $\mathrm{Hb}$ 's of the higher vertebrate, an Arg and a His residue have been detected as the Cterminus of the $\alpha$ chain and that of the $\beta$ chain, respectively. Therefore, as far as components $F_{1}$ and $F_{2}$ are concerned, the above comparison seems to be supported in this respect as well.

On the other hand, in the cases of components $S_{1}$ and $S_{2}$, which were demonstrated to possess only Arg residues as C-termini irrespective of the kind of polypeptide chain, no such support can be found. However, because the $\mathrm{N}$-terminal sequences of either chain are more or less common throughout the four $\mathrm{Hb}$ components as reported previously and because the acetylated chains of components $F_{1}$ and $F_{2}$ are comparable to the $\alpha$ chain of other vertebrate $\mathrm{Hb}$ as mentioned above, the acetylated chains of components $S_{1}$ and $S_{2}$ are considered to be also comparable to the $\alpha$ chain. And in turn, their valyl polypeptide chains are regarded as non- $\alpha$ chains, in other words, $\beta$ chains. In passing, components $S_{1}$ and $S_{2}$ seem to be the first Hb's which do not have His as $C$ terminal residues of $\beta$ chain, even though which of both polypeptide chains of each component is comparable to the $\beta$ chain of other vertebrate $\mathrm{Hb}$.

As for the interrelationship between the respiratory function of $\mathrm{Hb}$ and its molecular structure, an important significance of C-terminal His residues has recently been suggested basing on the observations with some mammalian Hb's: e.g., ANTONINI et al. ${ }^{4}$ noticed that the human $\mathrm{Hb}$ from which the $\mathrm{C}$-termini of $\beta$ chains were selectively eliminated by digestion with carboxypeptidase A, showed much less BoHr effect and much higher oxygen affinity, compared to the original $\mathrm{Hb}$.

It has already been elucidated ${ }^{7)}$ that component $F$ (and also each of $F_{1}$ and $F_{2}$; MATsUURA et al., unpublished) differs component $\mathrm{S}$ (and also each of $\mathrm{S}_{1}$ and $\mathrm{S}_{2}$; loc. cit.) in respiratory function: the former shows a large BoHR effect in contrast to the latter practically lacking in BoHR effect. In addition, the former exhibits lower oxygen affinity than the latter. That among the four $\mathrm{Hb}$ components of such respiratory functions, components $F_{1}$ and $F_{2}$ have His residues and in contrast, components $S_{1}$ and $S_{2}$ have Arg residues at the C-termini of the polypeptide chains comparable to the $\beta$ chains of other vertebrate $\mathrm{Hb}$ 's, seems to give a new and strong support to the above-mentioned suggestion.

\section{Acknowledgements}

The authors wish to express their sincere thanks to Mr. K. Muramatsu, Daikokuya Eel Co., Ltd., to Mr. Y. Kanazasu, Fukude Yogyo Co., Ltd., and to Dr. S. Yabe, Mr. Y. Noguch, and Mr. Y. MiYajima, Fuji Seifun Co., Ltd., for the supply of eel blood. 


\section{References}

1) H. Amano, K. Hashimoto, and F. Matsuura: This Bull., 34, 937-943 (1968).

2) H. Amano, K. Hashimoto, and F. Matsuura: ibid., 38, 345-350 (1972).

3) H. Amano, K. Hashmoto, and F. MatsuUra: ibid., 38, 351-357 (1972).

4) E. Antonin, J. Wrman, R. Zito, A. Rossi-Fanell, and A. Caputo: J. Biol. Chem., 236, PC 6063 (1961).

5) M. F. Perutz, H. Mutrhead, L. Mazzarella, R. A. Crowther, J. Greer, and J. V. Kilmartin: Nature, 222, 1240-1243 (1969).

6) J. V. KILMARTIN and J. F. Wootton: ibid., 228, 766-767 (1970).

7) K. Yamaguchi, Y. Kochinama, K. Hashimoto, and F. MatsuUra: This Bull., 28, 192-200 (1962).

8) C. J. Muller: Nature, 186, 643 (1960).

9) K. TAkAhashi: in "Seikagaku Kenkyuho" (T. ANDo et al., ed.), Vol. II, 531-534, Asakura Shoten, Tokyo (1967).

10) C. I. Niu and H. Fraenxel-Conrat: J. Am. Chem. Soc., 77, 5882-5885 (1955).

11) K. Hilse and G. Braunitzer: Z. Physiol. Chem., 349, 433-450 (1968). 